\title{
Pregnancy and the Risk of Severe COVID-19 Infection: Methodologic Challenges and Research Recommendations
}

\author{
David Savitz ${ }^{1}$, Angela Bengtson ${ }^{2}$, Erica Hardy ${ }^{3}$, and Deshayne Fell ${ }^{4}$ \\ ${ }^{1}$ Brown University \\ ${ }^{2}$ Brown University School of Public Health \\ ${ }^{3}$ Brown University Warren Alpert Medical School \\ ${ }^{4}$ University of Ottawa
}

April 7, 2021

\section{Hosted file}

Pregnancy and ID severity BJOG complete $4521 . p d f$ available at https://authorea.com/users/ 406388/articles/517067-pregnancy-and-the-risk-of-severe-covid-19-infection-methodologicchallenges-and-research-recommendations 